\section{Habitat Selection in Birds}

$\mathrm{T}$ $\mathrm{HE}$ afforestation of the Breckland heath with young pines provided David Lack ( $J$. Animal Ecol., Nov. 1933) with the opportunity of studying the changes in avifauna. Until the trees are some four years old, only the heathland birds occur, but within the next five years these disappear and are replaced by a new avifauna. The most marked features are the steady decrease of the skylark and the meadow pipit, and the appearance and rapid increase of the willow warbler.

Deficiency of nesting sites explains a few changes in the distributions ; thus the wheatear, common on open heaths and nesting exclusively in rabbit burrows, does not occur in afforested areas, which are rabbit-proof. Food, though clearly important in controlling the total bird population, does not appear to limit the distribution of any species investigated. The question of enemies can be ruled out, since man has destroyed almost all bird and egg-eating animals of the district. The most important appears to be the psychological factor, which is emphasised by the absence of certain species from areas, otherwise suitable, which do not supply them with a singing perch. Thus the requirements of the meadow pipit and the tree pipit are the same, but the latter occurs only in localities with fairly tall trees, or even in places with a single tree. Often, in the cases of closely related species, there appears nothing in the environment to cause the difference in distribution, and the remaining possibility is again the psychological factor.

When instinct appears to control such complex matters as nest building, it would be surprising if it did not control the type of ground selected by a bird for a breeding territory. The psychological nature of this instinctive habitat selection is often indicated by the fact that the height and not the nature of the vegetation is the determining factor. At times birds may successfully break away from the ancestral habitat.

Habitat selection may have some bearing on evolution. It is known that the passerine species of the north temperate region tend to occupy distinct but adjoining habitats, affording the same essential requirements, but differing in conspicuous features. Perhaps in this way two groups become isolated and eventually split into two species, as in the case of the meadow and the tree pipits.

\section{University and Educational Intelligence}

CAmbridge.-The Michael Foster studentship, offered annually for the encouragement of research in physiology, valued at 100 guineas, has been awarded to C. M. Fletcher, of Trinity College. The Wrenbury scholarship for study and research in economics, valued at $£ 100$, has been awarded to R. B. Bryce, of the University of Toronto and St. John's College.

At Clare College, the following elections to research studentships have been made: minor research studentship of $£ 100$ for two years, A. Marriage; Denman Baynes studentship of $£ 50$ for one year for chemistry, R. M. Barrer; Denman Baynes studentship of $£ 50$ for one year for physics, B. M. Crowther; roearch studentship of $£ 50$ for chemistry, I. Kemp.
EDINBURGH.- - At the graduation ceremonial on July 18 the Cameron Prize in practical therapeutics was awarded to Sir E. Sharpey-Schafer, emeritus professor in the University, in recognition of the advances in therapeutics arising out of his discoveries in endocrinology.

LeEds.-Mrs. Bolton has presented to the University a telescope and other scientific instruments belonging to her late son, Mr. Scriven Bolton, of Bramley, who began his astronomical career at the University Observatory.

Mr. K. Mitchell has been appointed assistant lecturer in applied mathematics as from the beginning of next session.

London.- The University has received from the Carnegie Corporation of New York an offer to provide 22,500 dollars annually for three years to aid the Institute of Education in developing its relations with students from the Dominions and Colonies. The sum is intended to provide fellowships for short periods to selected students from the Dominions, and to enable the Institute to invite a senior university teacher from one of the Dominions to hold for a limited period the post of adviser to overseas students.

The following appointments have been made :University chair of pharmacology (University College) (from July 1, 1935), Prof. J. H. Gaddum, since January, 1934, professor of pharmacology in the Egyptian University, Cairo. University chair of chemical pathology (London Hospital Medical College) (from October 1, 1934), Dr. J. R. Marrack, since 1919, lecturer in chemical pathology at the London Hospital Medical College. University readership in anthropology (London School of Economies) (from October 1, 1934), Dr. Raymond W. Firth, since 1933 , lecturer in anthropology at the London School of Economics.

Proposals for the establishment of an Institute of Archæology, and for its scheme of management, have been approved by the Senate, and Dr. R. E. Mortimer Wheeler has been appointed honorary director of the Institute.

Bilnngualism presents educational problems in various parts of the world which have been dealt with in various ways, determined in not a few instances more by political than by purely educational considerations. In the United States, these problems have to some extent been solved or cut through by 'Americanisation' schemes. In general, the view has prevailed that children speaking a foreign language should bo put as early as may be into school and, in so far as is possible, speak English only during the entire day. The use of the vernacular as a medium of education has been attempted experimentally at the San Jose School, which was reorganised as a training school for the use of the Education Department of the University of New Mexico in 1930. as part of a five-year programme of research in methods of education for Spanishspeaking pupils. Some account of this undertaking is given in Bulletin No. 11 of 1933 of the United States Office of Education, which reviews the whole subject of "The Education of Spanish-speaking Children in five South-Western States". This question has assumed in recent years a growing importance due to the rapid increase in these States of people of Mexican stock, the percentage of whom to the total population has increased from 1.9 in 1900 to $4 \cdot 2$ in 1910 and $9 \cdot 6$ in 1930 